\title{
The Membrane-Biofilm Reactor (MBfR) as a counter-diffusional biofilm process
}

\section{Robert Nerenberg}

Abstract

The membrane-biofilm reactor (MBfR), sometimes known as the membrane-aerated biofilm reactor (MABR), is an emerging treatment technology based on gas-transferring membranes. The membranes typically supply a gaseous electron donor or acceptor substrate, such as oxygen, hydrogen, and methane. The substrate diffuses through the membrane to a biofilm naturally forming on the membrane outer surface. The complementary substrate (electron donor or acceptor) typically diffuses from the bulk liquid into the biofilm, making MBfR counter diffusional. This paper reviews the unique behavior of counter-diffusional biofilms and highlights recent research on the MBfR. Key advances include insights into the microbial community structure of MBfRs, applying the MBfR to novel contaminants, providing a better understanding of biofilm morphology and its effects on MBfR behavior, and the development of methane-based MBfR applications. These advances are likely to further the development of the MBfR for environmental applications, such as energy-efficient wastewater treatment and advanced water treatment.

\section{Address}

Department of Civil and Environmental Engineering and Earth Sciences, University of Notre Dame, Notre Dame, IN 46556.

Corresponding Author: Nerenberg, Robert (Nerenberg.1@nd.edu) 


\section{Introduction}

Biofilms processes are of increasing interest in environmental biotechnology, mainly due to their ability to accumulate high biomass densities and retain biomass within the reactor [1]. Most existing biofilm processes are based on inert attachment surfaces, such as stone, pumice stone, dense plastic, or plastic foams. These can be called "co-diffusional" biofilms, as both electron donor and acceptor substrates are supplied from the bulk liquid (Figure 1a). However, biofilms can also develop on "reactive" surfaces that release an electron donor or acceptor substrate into the biofilm (Figure 1b). Because the electron donor and acceptor enter the biofilm from opposite sides, these are known as counter-diffusional biofilms.

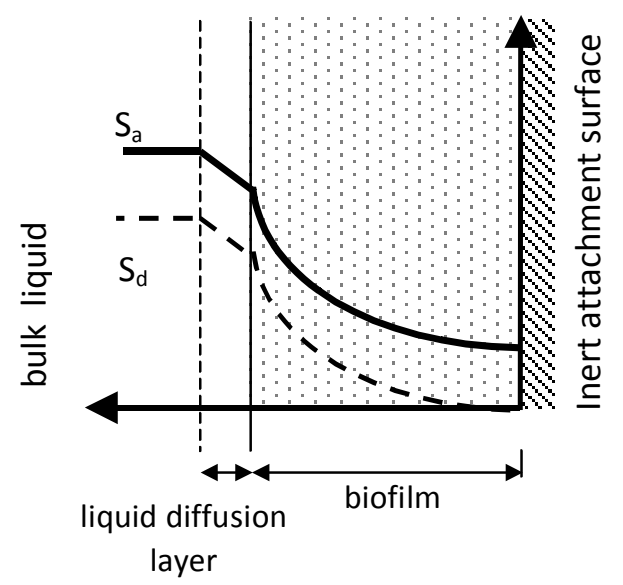

a) Co-diffusion in conventional biofilm

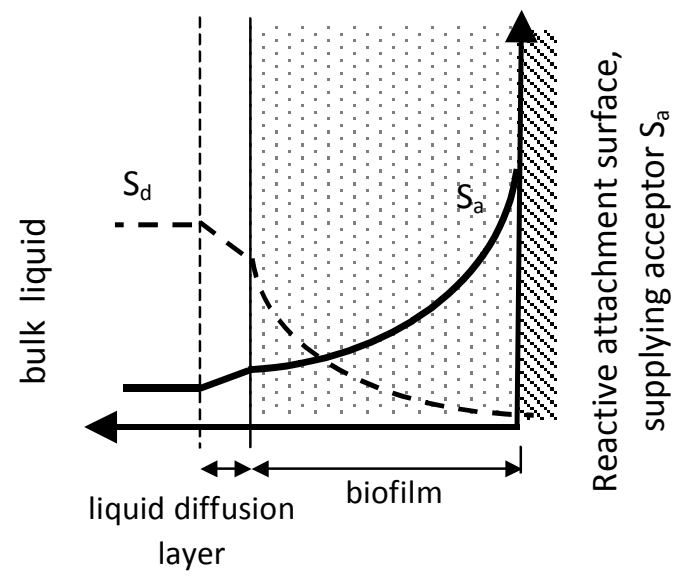

b) Counter-diffusion in MBfR biofilm

Fig. 1. a) Substrate gradients in a conventional, co-diffusional biofilm. b) Substrate gradients in a counter-diffusional MBfR biofilm. The bold line is the substrate released by the reactive surface (electron acceptor, $S_{a}$, in this case), while the dashed line indicates the substrate from the bulk liquid (electron donor, $S_{d}$, in this case).

Counter-diffusional biofilms can be found in natural and engineered systems. In natural systems, they can be found on gas-liquid interfaces, such as air bubbles or on plant roots, where the roots may provide organic exudates or oxygen to biofilms growing on their surface. Counterdiffusional biofilms also can develop on inorganic solids, such as elemental sulfur and pyrite, or organic solids, such as chitin and biodegradable polymers. $\left[2^{\bullet}-4\right]$ Even microbial electrochemical systems, such as microbial fuel cells, can behave as counter-diffusional biofilm processes. [ $\left.2^{\bullet}\right]$

An important counter-diffusional biofilm process in environmental biotechnology is the membrane-biofilm reactor (MBfR). The MBfR is based on gas-permeable membranes that deliver a gaseous substrate to biofilms naturally forming on the membrane outer surface. $\left[2^{\bullet}, 5^{\bullet \bullet}\right.$ ] When supplying air or oxygen, they often are called Membrane Aerated Biofilm Reactors 
(MABRs). $\left[5^{\bullet \bullet}, 6\right]$ This technology has been studied since the $1970 \mathrm{~s}$, but in recent years has received intense interest. Also, several MBfR and MABR commercial technologies have been launched in recent years, spurring further interest.

This paper reviews the basic principles of counter-diffusional biofilm behavior and the most recent developments on the MABR and MBfR processes.

\section{Special behavior of counter-diffusional biofilms}

With co-diffusional biofilms, the most metabolically active region of the biofilm is typically the exterior, where the electron donor and acceptor substrates are at their highest concentrations. In counter-diffusional biofilms, in contrast, one of the two substrates diffuses into the biofilm from the base, while the complementary substrate diffuses from the bulk liquid. [5 $5^{\bullet}$ ] Thus, the most active zone is typically located in the interior of the biofilm. This counter diffusion of donor and acceptor leads to unique behavior, including three key differences: development of unique microbial community structures, greater sensitivity to biofilm accumulation, and reduced susceptibility to liquid diffusion layer (LDL) resistance. Each item is discussed below.

- Development of unique microbial community structures. The counter diffusion of substrates can lead to unique microbial community structures in MBfRs. For example, in most biofilms for wastewater treatment, aerobic nitrifying microorganisms develop in the deeper biofilm regions, where the organic carbon concentration is lowest. While this location has minimized competition from heterotrophic microorganisms, it also is where the oxygen concentration is lowest, leading to low nitrification activity.[7] In an MABR system, oxygen is supplied from the base of the biofilm, so the nitrifiers experience low organic carbon and high oxygen concentrations, promoting high nitrification activity. Additionally, if the bulk liquid is left anoxic, then both nitrification and denitrification can take place within the same biofilm (Figure 2). [8] This unique stratification may favor suppression of nitrite-oxidizing organisms (NOB).[7]

- Greater sensitivity to biofilm accumulation. In conventional biofilms, the initial contaminant transformation fluxes are low, due to low biofilm thicknesses. The fluxes then increase as the biofilm thickness increases, until the biofilm growth is balanced by decay and detachment. In counter-diffusional biofilms, fluxes increase up to a point, but then decrease as the thickness increases further. This is because of donor and acceptor counter diffusion. The biofilm interior has low activity due to the limitation of one substrate, while the exterior has low rates due to the limitation of the other. Thus, careful management of biofilm accumulation is needed to maintain high fluxes. [5 ${ }^{\bullet \bullet}$ ]

- Lower susceptibility to liquid diffusion layer resistance. In a conventional biofilm, the LDL limits substrate fluxes into the biofilm. As the biofilm thickness and flux increase, the LDL provides mass transfer resistance and limits further biofilm growth. Higher bulk substrate concentrations are needed to overcome the LDL resistance. In contrast, in a counter-diffusional biofilm, the LDL provides a barrier to loss of the internal substrate to 
the bulk liquid. Thus, as long as the substrate from the bulk is present at non-ratelimiting concentrations, the LDL will not limit, and may actually enhance, microbial activity. $\left[5^{\bullet \bullet}\right]$

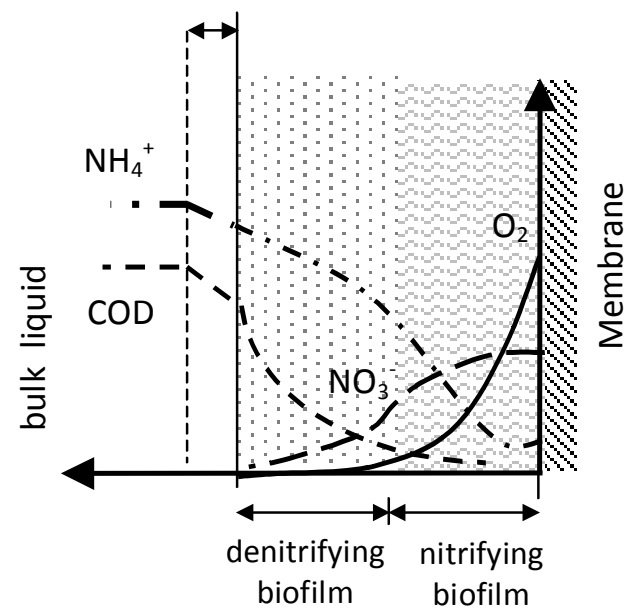

Fig. 2. Substrate gradients in an MABR for Chemical oxygen demand (COD) oxidation, nitrification, and denitrification. Note that nitrifying bacteria are located in the interior, where they have access to high oxygen concentrations, and heterotrophic denitrifiers can grow using nitrate formed by nitrifiers and COD diffusing from the exterior of the biofilm. Thus, concurrent nitrification and denitrification is easily achieved.

In addition to the above, the mode of gas supply and biofilm development in MBfRs can lead to special behavior. [ $5^{\bullet \bullet}$ ] For example, when gas is supplied via hollow-fiber membranes, other dissolved gases in the bulk liquid, or gases formed in the biofilm, can diffuse back into the membrane, diluting the supply gas. When operating an MBfR with sealed membranes, these gases concentrate at the distal end of the membrane, decreasing its effectiveness and leading to thinner biofilms. Also, several hollow-fiber membranes can clump together, effectively forming one large biofilm with individual membranes providing point gas sources in the biofilm interior. Finally, substrate counter diffusion can impact biofilm properties such as diffusivity and mechanical resistance. All these effects are distinct from conventional biofilm processes and can be important in understanding and predicting process behavior. Further research should assess these effects.

The following sections address the most recent research on the MBfR and MABR.

\section{Biofilm morphology and MBfR performance}

Biofilms can assume uneven or rough morphologies, which result from an interplay between cell growth rates, shear conditions, microbial cell types, and other factors. The roughness of counterdiffusional biofilms can impact their behavior. In particular, roughness increases the effective LDL thickness, which limits fluxes in conventional biofilms. [9] As explained above, in counterdiffusional biofilms, the LDL does not limit the substrate supplied from within the biofilm, so 
roughness is not necessarily detrimental. Recent work has demonstrated this experimentally and with modeling.[10]

The fluid flow regime is important for all biofilm processes. Thus, computational fluid dynamics can be an important tool for MBfR studies, either to determine the flow regime around membranes, or to couple with a model of biofilm growth and deformation.[11,12] This can be especially important when biofilm-covered membranes contact each other, as they may bundle and cause dead zones without flow. As mentioned previously, the bundle may behave like a single biofilm with gaseous substrates sources in the interior. [1 $\left.3^{\bullet}\right]$

It may be important to consider the coupled effects of biofilm development and fluid flow and shear. Biofilm development can alter the fluid flow patterns, while flow-induced shear can determine the biofilm morphology.[12,14] This is important for mass transfer in and out of the biofilm, but morphology and detachment can also impact the microbial community structure. $\left[15^{\bullet \bullet}\right]$

There is an increasing interest in biofilm mechanical properties, and new models are being developed to incorporate these properties to predict deformation and detachment.[16-18] Some recent studies have determined mechanical properties for MABR biofilms. These can differ significantly from conventional biofilms, but these have not yet been included in mechanical models. $\left[12,19^{\bullet \bullet}\right]$

\section{MABR}

Much research has focused on MABRs for removal of COD and nitrogen.[5 $\left.5^{\bullet \bullet}, 6\right]$ Prior research has shown that concurrent nitrification and denitrification can be achieved in MABRs, that nitrification is less susceptible to BOD inhibition, and that short cut nitrogen removal, via nitrite, can be achieved.[8] Membrane fouling from excess biomass accumulation is a concern. [5 $\left.{ }^{\bullet \bullet}\right]$ More recent research has confirmed these findings, and explored MAB performance for other types of matrices, such as landfill leachate, oil field wastewater, and pharmaceutical wastewater. $\left[13^{\bullet}, 20-22^{\bullet}, 23,24\right]$ Some research also confirmed the ability of the MABR to achieve biological phosphorus removal, when operated in sequencing batch mode with a biofilm removal stage. $\left[25^{\circ}\right]$ Several types of new process configurations have been developed, for example combining MABRs with ozone, powdered activated carbon, and coagulation flocculation, to enhance removal of recalcitrant organics.[20,23,26] New membrane materials were also studied to improve cell adhesion and gas transfer.[24] Also, some studies addressed the microbial community structure of MABRs for removal of COD, nitrification and denitrification, as well as the need to model nitrite as an intermediate.[27,28]

Gas transfer is key for MABRs. High oxygen transfer efficiencies (OTEs) can be obtained with closed end operation. However, closed end operation is subject to gas back diffusion, which results in lower oxygen transfer rates (OTRs). $\left[5^{\bullet \bullet}\right]$ Gas back-diffusion has been studied previously for clean, closed end membranes, but little has been done for membranes with biofilms. Recent research has addressed the effects of biofilm on oxygen transfer in an MABR, 
and the interplay of OTE and OTR were addressed in pilot scale research.[13 $\left.3^{\bullet}, 29,30\right]$ Further research is needed to explore the effect of biofilm on back-diffusion in closed end membranes, as well as the effects of partially opened membranes or transient effects of opening and closing membranes. Optimal operational strategies may be developed from these approaches.

A major benefit of the MABR is savings in energy costs. It is difficult to quantify the savings without full scale data, but pilot scale data and modeling can be used as a first approximation. Studies suggest that the MABR can be up to $86 \%$ more energy efficient than conventional activated sludge. $\left[13^{\bullet}, 31^{\bullet}\right]$ The major factors affecting cost savings are the cost of electricity, the membrane cost, membrane durability, and MABR removal fluxes. Future research should explore these items in more detail.

Some recent research has addressed the use of MABRs for autotrophic nitrogen removal via Anammox microorganisms. A challenges for Anammox processes is achieving nitritation, avoiding the proliferation of NOB. This is especially challenging for mainstream wastewater treatment systems. Research has shown nitritation can be obtained by cycling the oxygen supply, and that this operation also results in reduced emissions of nitric and nitrous oxide.[32-

$34^{\bullet}$ ] However, others have shown it is possible to achieve nitritation in an MABR with continuous aeration.[35]

An exciting development is that several companies have developed commercial MABR applications, including Oxymem, GE, and Emefcy. This is likely to further catalyze research interest on the MABR.

\section{$\mathrm{H}_{2}$-based MBfR}

One of the major applications of the MBfR is to supply $\mathrm{H}_{2}$ as an electron donor for denitrification, and to a lesser extent to achieve the reduction of perchlorate and other oxidized contaminants. $\left[5^{\bullet \bullet}\right]$ When removing perchlorate or other trace contaminants concurrently with nitrate, a concern is that their reduction may be slowed or inhibited by nitrate.[36] Yet if no nitrate is present, there may not be enough primary electron acceptor to sustain the competent population. Also, if nitrate is driven to very low levels, sulfate-reducing bacteria and methanogens may proliferate, leading to undesirable byproducts $\left[15^{\circ \bullet}\right]$. A two-stage MBfR was studied as a means to reduce the nitrate concentration so that appropriate levels were obtained in the second stage.[37-41 ${ }^{\bullet}$ Sulfate-reducing bacteria were found to persist along with the denitrifying bacteria, even though sulfate reduction was minimal due to $\mathrm{H}_{2}$ limitation. Modeling was also used to show that appropriate management of biofilm thickness and detachment were needed. $\left[12,15^{\circ}\right]$ Multidimensional modeling revealed unexpected interactions between sulfate reducing bacteria and denitrifying bacteria, which in turn were affected by the geometry of the membrane assembly. [15*0] The curvature of the membranes provided protected niches with high $\mathrm{H}_{2}$ concentrations and little detachment, allowing these undesirable species to proliferate

Several contaminants were shown to be effectively removed by the $\mathrm{H}_{2}-\mathrm{MBfR}$, including parachlorobenzene and tetrachloroethene, and other studies addressed the microbial communities carrying out selenate reduction.[42-44] Novel membrane configurations were also explored, either supplying $\mathrm{CO}_{2}$ in separate membranes or placing $\mathrm{H}_{2}$-supplying membranes separately 
from a bioreactor to allow the membranes to be chemically cleaned without disrupting the biological process. [45,46]

A commercial version of the $\mathrm{H}_{2}$-MBfR was launched by APTwater, although due to mergers and changes in management, it is not clear if they will continue to produce their MBfR technology.

\section{$\mathrm{CH}_{4}$-based MBfR}

A novel MBfR application is to supply methane $\left(\mathrm{CH}_{4}\right)$ to drive reduction processes, in a similar fashion to the $\mathrm{H}_{2}$-based MBfR. This process relies on recently discovered methane-oxidizing microorganisms known as denitrifying anaerobic methane oxidation (DAMO) microorganisms. The process is sometimes called "nitrate/nitrite-dependent anaerobic methane oxidation" (nDAMO). Researchers have shown n-DAMO is achievable in a, MBfR supplied with methane. $\left[47-49^{\bullet}\right]$ Methane has also been shown to serve as a donor for perchlorate reduction. Although the methane-based processes seem to be much slower than those based on $\mathrm{H}_{2}$, this is an exciting new direction for MBfRs and is likely to receive much interest over the next few years.

\section{Conclusions}

The MBfR and MABR are technologies that are approaching maturity and are now available at the commercial scale. A surge in research, both fundamental and applied, has been seen globally in recent years. This is leading to a better understanding of the special behavior of the MBfR, as well as new applications. Future research should address the improved methods of biofilm management, possibly addressing the biofilm mechanical properties, the effect of back-diffusion on closed end membranes, membrane costs, membrane durability, MABR removal fluxes, and new applications, such as methane-based processes.

\section{Acknowledgements}

R. Nerenberg was partially funded by NSF project CBET0954918 (Nerenberg CAREER award) and WERF grant U2R14.

\section{References and recommended reading}

Papers of particular interest, published within the period of review, have been highlighted as:

of special interest

$\bullet$ of outstanding interest

[1] Nicolella C, van Loosdrecht MCM, Heijnen JJ: Wastewater treatment with particulate biofilm reactors. J Biotechnol 2000, 80:1-33. 
[2] Di Capua F, Papirio S, Lens PNL, Esposito G: Chemolithotrophic denitrification in biofilm reactors. Chem Eng $J$ 2015, 280:643-657.

$\bullet$ Provides a review of chemolithotrophic denitrification, including the $\mathrm{H}_{2}-\mathrm{MBfR}$ and several insoluble compounds that may behave as counter-diffusional biofilms.

[3] Shen Z, Zhou Y, Wang J: Comparison of denitrification performance and microbial diversity using starch/polylactic acid blends and ethanol as electron donor for nitrate removal. Bioresour Technol 2013, 131:33-39.

[4] Robinson-Lora MA, Brennan RA: The use of crab-shell chitin for biological denitrification: Batch and column tests. Bioresour Technol 2009, 100:534-541.

[5] Martin KJ, Nerenberg R: The membrane biofilm reactor (MBfR) for water and wastewater treatment: Principles, applications, and recent developments. Bioresour Technol 2012, 122:83-94.

${ }^{\bullet}$ Provides a comprehensive review of MBfR and MABR technologies.

[6] Syron E, Casey E: Membrane-aerated biofilms for high rate biotreatment: Performance appraisal, engineering principles, scale-up, and development requirements. Environ Sci Technol 2008, 42:1833-1844.

[7] Vo GD, Brindle E, Heys J: An experimentally validated immersed boundary model of fluidbiofilm interaction. Water Sci Technol 2010, 61:3033-3040.

[8] Downing LS, Nerenberg R: Effect of bulk liquid BOD concentration on activity and microbial community structure of a nitrifying, membrane-aerated biofilm. Appl Microbiol Biotechnol 2008, $81: 153-162$.

[9] Picioreanu C, van Loosdrecht MCM, Heijnen JJ: A theoretical study on the effect of surface roughness on mass transport and transformation in biofilms. Biotechnol Bioeng 2000, 68:355-369.

[10] Pavissich JP, Aybar M, Martin KJ, Nerenberg R: A methodology to assess the effects of biofilm roughness on substrate fluxes using image analysis, substrate profiling, and mathematical modelling. Water Sci Technol 2014, 69:1932-1941.

[11] Plascencia-Jatomea R, Almazan-Ruiz FJ, Gomez J, Rivero EP, Monroy O, Gonzalez I: Hydrodynamic study of a novel membrane aerated biofilm reactor (MABR): Tracer experiments and CFD simulation. Chem Eng Sci 2015, 138:324-332.

[12] Martin KJ, Picioreanu C, Nerenberg R: Multidimensional modeling of biofilm development and fluid dynamics in a hydrogen-based, membrane biofilm reactor (MBfR). Water Res 2013, 47:47394751 .

[13] Syron E, Semmens MJ, Casey E: Performance analysis of a pilot-scale membrane aerated biofilm reactor for the treatment of landfill leachate. Chem Eng $J$ 2015, 273:120-129.

- Pilot-scale studies on MABR for treating landfill leachate. Assess the benefits of supply pure oxygen vs. air, nitrite accumulation, energy savings, and the potential effects of membrane bundling 
[14] Picioreanu C, Vrouwenvelder JS, van Loosdrecht MCM: Three-dimensional modeling of biofouling and fluid dynamics in feed spacer channels of membrane devices. J Membr Sci 2009, 345:340-354.

[15] Martin KJ, Picioreanu C, Nerenberg R: Assessing microbial competition in a hydrogen-based membrane biofilm reactor (MBfR) using multidimensional modeling. Biotechnol Bioeng 2015, 112:1843-1853.

- Uses 2-D modeling of flow, substratum geometry, and biofilm development to assess the competition of denitrifying, sulfate-reducing and methanogenic microorganisms in a $\mathrm{H}_{2}-\mathrm{MBfR}$. The modeling shows the uneven substratum that delivers $\mathrm{H}_{2}$ can be more favorable to undesirable sulfate-reducing and methanogenic microorganisms

[16] Tierra G, Pavissich JP, Nerenberg R, Xu Z, Alber MS: Multicomponent model of deformation and detachment of a biofilm under fluid flow. J Roy Soc Interface 2015, 12:20150045.

[17] Horn H, Lackner S: Modeling of biofilm systems: a review. Adv Biochem Eng Biot 2014, 146:5376.

[18] Boel M, Ehret AE, Albero AB, Hellriegel J, Krull R: Recent advances in mechanical characterisation of biofilm and their significance for material modelling. Crit Rev Biotechnol 2013, $33: 145-171$.

[19] Pellicer-Nacher C, Smets BF: Structure, composition, and strength of nitrifying membraneaerated biofilms. Water Res 2014, 57:151-161.

• Shows that MABR biofilms can be very different from conventional biofilms with respect to porosities, densities, and cohesive strength. These, in turn, are affected by shear stress and substrate loadings

[20] Tian H, Zhang H, Li P, Sun L, Hou F, Li B: Treatment of pharmaceutical wastewater for reuse by coupled membrane-aerated biofilm reactor (MABR) system. $R$. Soc. Chem. Adv. 2015, 5:6982969838.

[21] Wei X, Li B, Zhao S, Wang L, Zhang H, Li C, Wang S: Mixed pharmaceutical wastewater treatment by integrated membrane-aerated biofilm reactor (MABR) system - A pilot-scale study. Bioresour Technol 2012, 122:189-195.

[22] Peng L, Chen X, Xu Y, Liu Y, Gao S, Ni B: Biodegradation of pharmaceuticals in membrane aerated biofilm reactor for autotrophic nitrogen removal: A model-based evaluation. $J \mathrm{Membr} S c i$ 2015, 494:39-47.

-Use modeling to assess the degradation of pharmaceuticals in an MABR by ammonia oxidizing bacteria (AOB) and heterotrophs

[23] Li P, Zhao D, Zhang Y, Sun L, Zhang H, Lian M, Li B: Oil-field wastewater treatment by hybrid membrane-aerated biofilm reactor (MABR) system. Chem Eng $J$ 2015, 264:595-602. 
[24] Hou F, Li B, Xing M, Wang Q, Hu L, Wang S: Surface modification of PVDF hollow fiber membrane and its application in membrane aerated biofilm reactor (MABR). Bioresour Technol 2013, 140:1-9.

[25] Sun L, Wang Z, Wei X, Li P, Zhang H, Li M, Li B, Wang S: Enhanced biological nitrogen and phosphorus removal using sequencing batch membrane-aerated biofilm reactor. Chemical Engineering Science 2015, 135:559-565.

- Compare enhanced biological phosphorus removal in a continuous MABR to a sequencing batch MABR with intermittent aeration, step feed, and periodic biofilm removal. The sequencing operation allows high levels of phosphorus removal.

[26] Plascencia-Jatomea R, Gonzalez I, Gomez J, Monroy O: Operation and dynamic modeling of a novel integrated anaerobic-aerobic-anoxic reactor for sewage treatment. Chem Eng Sci 2015, 138:31-40.

[27] Tian H, Zhao J, Zhang H, Chi C, Li B, Wu X: Bacterial community shift along with the changes in operational conditions in a membrane-aerated biofilm reactor. Appl Microbiol Biotechnol 2015, 99:3279-3290.

[28] Landes N, Morse A, Jackson WA: Including nitrite as an intermediate in simultaneous nitrification/denitrification membrane-aerated biofilm reactor models. Environ Eng Sci 2013, 30:606-616.

[29] Pellicer-Nacher C, Domingo-Felez C, Lackner S, Smets BF: Microbial activity catalyzes oxygen transfer in membrane-aerated nitritating biofilm reactors. $J$ Membr Sci 2013, 446:465-471.

[30] Cerqueira AC, Nobrega R, Sant'Anna GL, Jr., Dezotti M: Oxygen air enrichment through composite membrane: application to an aerated biofilm reactor. Brazil J Chem Eng 2013, 30:771779 .

[31] Aybar M, Pizarro G, Boltz JP, Downing L, Nerenberg R: Energy-efficient wastewater treatment via the air-based, hybrid membrane biofilm reactor (hybrid MfBR). Water Sci Technol 2014, 69:1735-1741.

- Provides estimated of cost and energy benefits of the MABR, along with the identification of the parameters with the greatest impact on cost and energy. These parameters are recommended for better quantification.

[32] Ma B, Bao P, Wei Y, Zhu G, Yuan Z, Peng Y: Suppressing nitrite-oxidizing bacteria growth to achieve nitrogen removal from domestic wastewater via anammox using intermittent aeration with low dissolved oxygen. Sci Rep 2015, 5:13048.

[33] Dunsmore B, Jacobsen A, Hall-Stoodley L, Bass C, Lappin-Scott H, Stoodley P: The influence of fluid shear on the structure and material properties of sulphate-reducing bacterial biofilms. $J$ Ind Microbiol Biotechnol 2002, 29:347-353. 
[34] Ni B, Smets BF, Yuan Z, Pellicer-Nacher C: Model-based evaluation of the role of Anammox on nitric oxide and nitrous oxide productions in membrane aerated biofilm reactor. $J$ Membr Sci 2013, 446:332-340.

-This modeling study suggests that the MABR for nitritation/Anammox would be likely to produce less $\mathrm{N}_{2} \mathrm{O}$ than a co-diffusional biofilm.

[35] Gilmore KR, Terada A, Smets BF, Love NG, Garland JL: Autotrophic Nitrogen Removal in a Membrane-Aerated Biofilm Reactor Under Continuous Aeration: A Demonstration. Environ Eng Sci 2013, 30:38-45.

[36] Nerenberg R, Kawagoshi Y, Rittmann BE: Microbial ecology of a perchlorate-reducing, hydrogen-based membrane biofilm reactor. Water Res 2008, 42:1151-1159.

[37] Ontiveros-Valencia A, Tang Y, Krajmalnik-Brown R, Rittmann BE: Managing the interactions between sulfate-and perchlorate-reducing bacteria when using hydrogen-fed biofilms to treat a groundwater with a high perchlorate concentration. Water Res 2014, 55:215-224.

[38] Ontiveros-Valencia A, Ilhan ZE, Kang D, Rittmann B, Krajmalnik-Brown R: Phylogenetic analysis of nitrate- and sulfate-reducing bacteria in a hydrogen-fed biofilm. FEMS Microbiol Ecol 2013, $85: 158-167$.

[39] Ontiveros-Valencia A, Tang Y, Zhao H, Friese D, Overstreet R, Smith J, Evans P, Rittmann BE, Krajmalnik-Brown R: Pyrosequencing Analysis yields comprehensive assessment of microbial communities in pilot-scale two-stage membrane biofilm reactors. Environ Sci Technol 2014, 48:75117518 .

[40] Zhao H, Ontiveros-Valencia A, Tang Y, Kim B, VanGinkel S, Friese D, Overstreet R, Smith J, Evans P, Krajmalnik-Brown R, Rittmann B: Removal of multiple electron acceptors by pilot-scale, two-stage membrane biofilm reactors. Water Res 2014, 54:115-122.

[41] Zhao H, Ontiveros-Valencia A, Tang Y, Kim B, Ilhan ZE, Krajmalnik-Brown R, Rittrnann B: Using a two-stage hydrogen-based membrane biofilm reactor (MBfR) to achieve complete perchlorate reduction in the presence of nitrate and sulfate. Environ Sci Technol 2013, 47:1565-1572.

- This work shows that a greater removal of perchlorate (a secondary substrate) can be obtained by separating a $\mathrm{H}_{2}-\mathrm{MBfR}$ into two stages. In the first, nitrate (a primary substrate) is substantially reduced. This leaves a more suitable environment for perchlorate reduction in the second stage.

[42] Li H, Zhang Z, Xu X, Liang J, Xia S: Bioreduction of para-chloronitrobenzene in a hydrogenbased hollow-fiber membrane biofilm reactor: effects of nitrate and sulfate. Biodegradation 2014, 25:205-215.

[43] Karatas S, Hasar H, Taskan E, Ozkaya B, Sahinkaya E: Bio-reduction of tetrachloroethen using a H-2-based membrane biofilm reactor and community fingerprinting. Water Res 2014, 58:21-28.

[44] Lai C, Yang X, Tang Y, Rittmann BE, Zhao H: Nitrate shaped the selenate-reducing microbial community in a hydrogen-based biofilm reactor. Environ Sci Technol 2014, 48:3395-3402. 
[45] Xia S, Wang C, Xu X, Tang Y, Wang Z, Gu Z, Zhou Y: Bioreduction of nitrate in a hydrogen31276:59-64.

[46] Li P, Xing W, Zuo J, Tang L, Wang Y, Lin J: Hydrogenotrophic denitrification for tertiary nitrogen removal from municipal wastewater using membrane diffusion packed-bed bioreactor. Bioresour Technol 2013, 144:452-459.

[47] Chen X, Guo J, Xie G, Liu Y, Yuan Z, Ni B: A new approach to simultaneous ammonium and dissolved methane removal from anaerobic digestion liquor: A model-based investigation of feasibility. Water Res 2015, 85:295-303.

[48] Chen X, Guo J, Shi Y, Hu S, Yuan Z, Ni B: Modeling of simultaneous anaerobic methane and ammonium oxidation in a membrane biofilm reactor. Environ Sci Technol 2014, 48:9540-9547.

[49] Shi Y, Hu S, Lou J, Lu P, Keller J, Yuan Z: Nitrogen removal from wastewater by coupling anammox and methane-dependent denitrification in a membrane biofilm reactor. Environ Sci Technol 2013, 47:11577-11583.

- This study assesses the use of a $\mathrm{CH}_{4}$-MBfR for combined nitritation/anammox. 

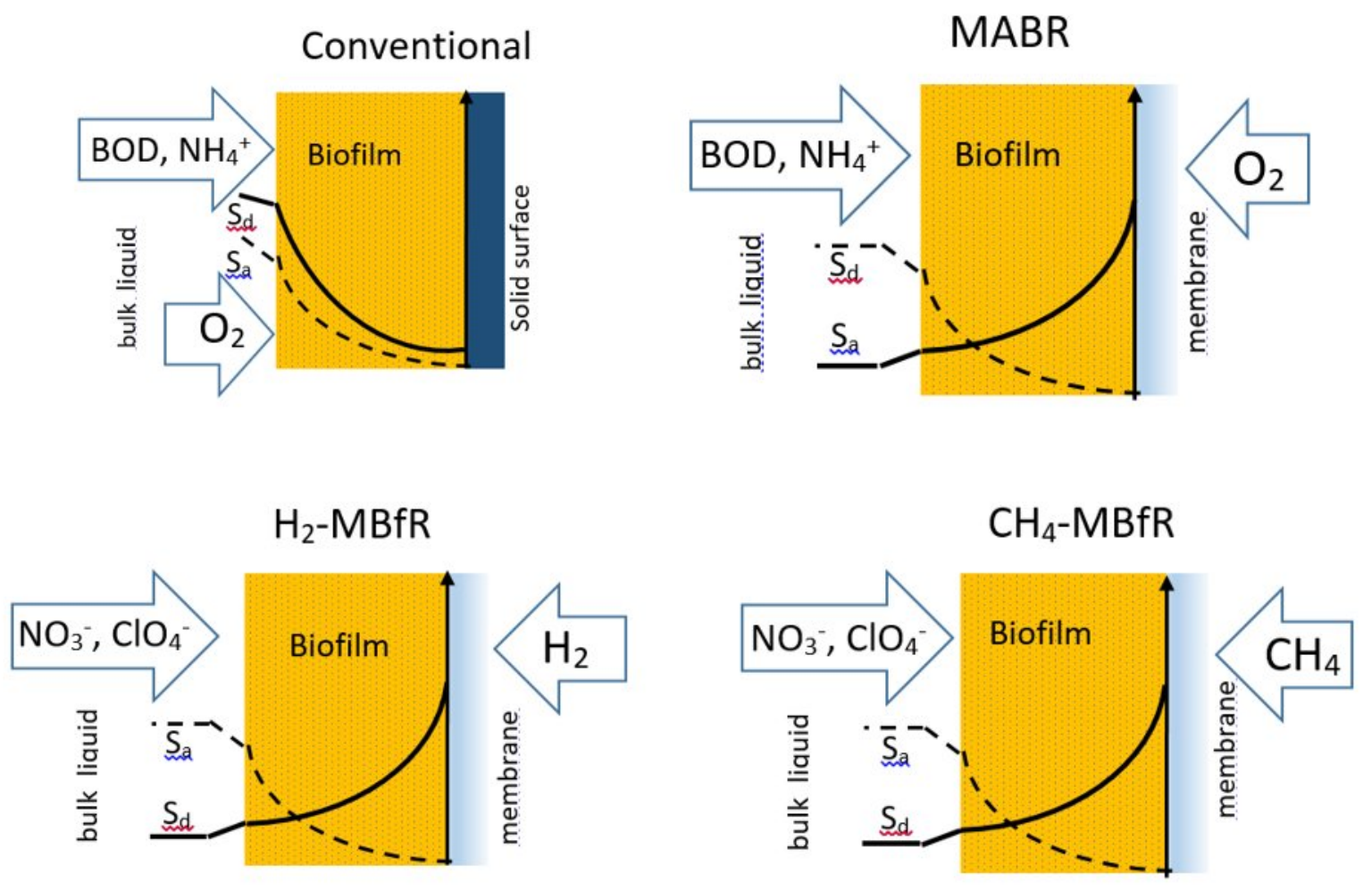

Graphical Abstract 